\title{
Frovatriptan vs. other triptans for the acute treatment of oral contraceptive-induced menstrual migraine: pooled analysis of three double-blind, randomized, crossover, multicenter studies
}

\author{
G. Allais $\cdot$ V. Tullo $\cdot$ S. Omboni $\cdot$ D. Pezzola . \\ D. Zava $\cdot$ C. Benedetto $\cdot$ G. Bussone
}

(C) The Author(s) 2013. This article is published with open access at Springerlink.com

\begin{abstract}
Oral contraceptive-induced menstrual migraine (OCMM) is a particularly severe form of migraine triggered by the cyclic hormone withdrawal. To review the efficacy of frovatriptan vs. other triptans, in the acute treatment of OCMM through a pooled analysis of three individual randomized Italian studies. With or without aura migraineurs were randomized to frovatriptan $2.5 \mathrm{mg}$ or rizatriptan $10 \mathrm{mg}$ (study 1), frovatriptan $2.5 \mathrm{mg}$ or zolmitriptan $2.5 \mathrm{mg}$ (study 2), frovatriptan $2.5 \mathrm{mg}$ or almotriptan $12.5 \mathrm{mg}$ (study 3 ). All studies had a multicenter, randomized, double-blind, crossover design. After treating 1-3 episodes of migraine in 3 months with the first treatment, patients switched to the other treatment for the next 3 months. In this analysis, the subset of 35 of the 280 women of the intention-to-treat population taking combined oral contraceptives and experiencing a migraine attack during the withdrawal phase, were analyzed. The proportion of pain free and pain relief at $2 \mathrm{~h}$ were 25 and $51 \%$ with frovatriptan and 28 and $48 \%$ with comparators $(p=\mathrm{NS})$. At $24 \mathrm{~h}, 71$ and $83 \%$ of frovatriptan-treated
\end{abstract}

G. Allais $(\bowtie) \cdot$ C. Benedetto

Department of Gynecology and Obstetrics, Women's Headache Center, University of Turin, Via Ventimiglia 3,

10126 Turin, Italy

e-mail: gb.allais@tiscali.it

V. Tullo $\cdot$ G. Bussone

Department of Clinical Neuroscience, National Neurological Institute Carlo Besta, Milan, Italy

S. Omboni

Clinical Research Unit, Italian Institute of Telemedicine,

Varese, Italy

D. Pezzola $\cdot$ D. Zava

Medical Department, Istituto Lusofarmaco D’Italia, Milan, Italy patients and 60 and $76 \%$ of comparator-treated patients were pain free ( $p<0.05$ between treatments) and had pain relief ( $p=\mathrm{NS}$ ), respectively. Relapse at 24 and $48 \mathrm{~h}$ was significantly $(p<0.05)$ lower with frovatriptan $(17$ and $21 \%$ ) than with the comparators (27 and $31 \%$ ). Our results suggest that, due to its sustained antimigraine effect, frovatriptan may be particularly suitable for the management of OCMM than other triptans.

Keywords Almotriptan - Estrogen withdrawal · Frovatriptan · Oral-contraceptive induced menstrual migraine $\cdot$ Rizatriptan $\cdot$ Zolmitriptan

\section{Introduction}

Oral contraceptive-induced menstrual migraine (OCMM) is a menstrual migraine subtype mainly caused by estrogen withdrawal occurring during the week of pill suspension [1, 2]. OCMM is a poorly studied, but particularly severe and disabling form of menstrual migraine [3]; it is codified by the ICHDII classification as estrogen-withdrawal headache (code 8.4.3) [2].

Evidence-based guidelines recommend treating moderate or severe migraine, including menstrual migraine, with migraine-specific agents [4]. Among these, triptans are considered to provide a greater clinical benefit and a more favorable adverse event profile than other anti-migraine drugs [4].

Frovatriptan is a second-generation triptan, with a distinct pharmacokinetic profile. Its high selectivity for the cerebral vasculature, long elimination half life and high persistence of therapeutic action may be useful in preventing menstrual migraine, but also for treating acute attacks, as shown by several randomized trials [4-7]. 
Although frovatriptan is currently among the triptans recommended for prevention of menstrual migraine [8-10], its efficacy in OCMM has had limited investigation [11]. In the present retrospective analysis, we report on a pooled individual data analysis of three randomized double-blind studies [12-14] performed to verify whether frovatriptan may be effective in the acute management of an OCMM attack and whether its efficacy may differ from that of other triptans.

\section{Methods}

Study population and design

Information on the study design for the three original studies is reported in the main publications [12-14]. In brief, the studies recruited subjects of both genders, aged 18-65 years, with a current history of migraine with or without aura, according to the International Headache Society definition [2], and with at least one, but no more than six migraine attacks per month for 6 months prior to entering the study. In the present retrospective analysis, only the group of women with OCMM was taken into consideration. OCMM was defined according to IHS criteria, as an estrogen-withdrawal headache, namely a migraine without aura developing within 5 days after cessation of estrogen use and resolving within 3 days [2]. Estrogen use must have lasted for at least 3 weeks prior to cessation. Patients taking all types of combined oral contraceptives, except those entailing a withdrawal period of less than 5 days, were considered eligible for inclusion in the present retrospective analysis.

The studies had a multicenter, randomized, double blind, cross-over design. A total of 33 different Italian centers were involved in the studies. Each patient received frovatriptan $2.5 \mathrm{mg}$ or rizatriptan $10 \mathrm{mg}$ in the first study [12], frovatriptan $2.5 \mathrm{mg}$ or zolmitriptan $2.5 \mathrm{mg}$ in the second study [13], and frovatriptan $2.5 \mathrm{mg}$ or almotriptan $12.5 \mathrm{mg}$ in the third study [14], in a randomized sequence. After treating 1-3 episodes of migraine in no more than 3 months with the first treatment, the patient switched to the other treatment and was asked to treat a maximum of three episodes of migraine in no more than 3 months with the second treatment.

The study design foresaw three visits and each patient's participation time in the study had not to exceed 6 months from randomization. Subjects having no migraine episodes during one of the two observation periods were excluded from the study.

Randomization was done by blocks of four. Blindness ensured by the overencapsulation technique, i.e., by inserting study drug tablets in capsules.
Data analysis

The present pooled analysis was carried out in all women with OCMM, who treated at least one episode of OCMM with both medications in each study.

The following endpoints were evaluated: (a) the proportion of pain-free episodes at 2 and $24 \mathrm{~h}$ (absence of migraine episodes 2 and $24 \mathrm{~h}$ after intake of one dose of study drug); (b) the proportion of pain-relief episodes at 2 and $24 \mathrm{~h}$ (a decrease in migraine intensity from severe or moderate to mild or none 2 and $24 \mathrm{~h}$ after the intake of one study drug dose); (c) relapse within 24 and $48 \mathrm{~h}$ (defined as an episode of migraine occurring within 24 and $48 \mathrm{~h}$ from the previous episode, after a period without migraine).

Continuous variables were summarized by computing average values and standard deviations (SD), while categorical variables by computing the absolute value and the frequency (as percentage). Study endpoints were compared between groups by a Student's $t$ test (continuous variables) or by a $\chi^{2}$ test (categorical variables). The level of statistical significance was kept at 0.05 for all analyses.

\section{Results}

The main study population consisted of 346 subjects, of which $280(81 \%)$ were women and 224 were in the fertile

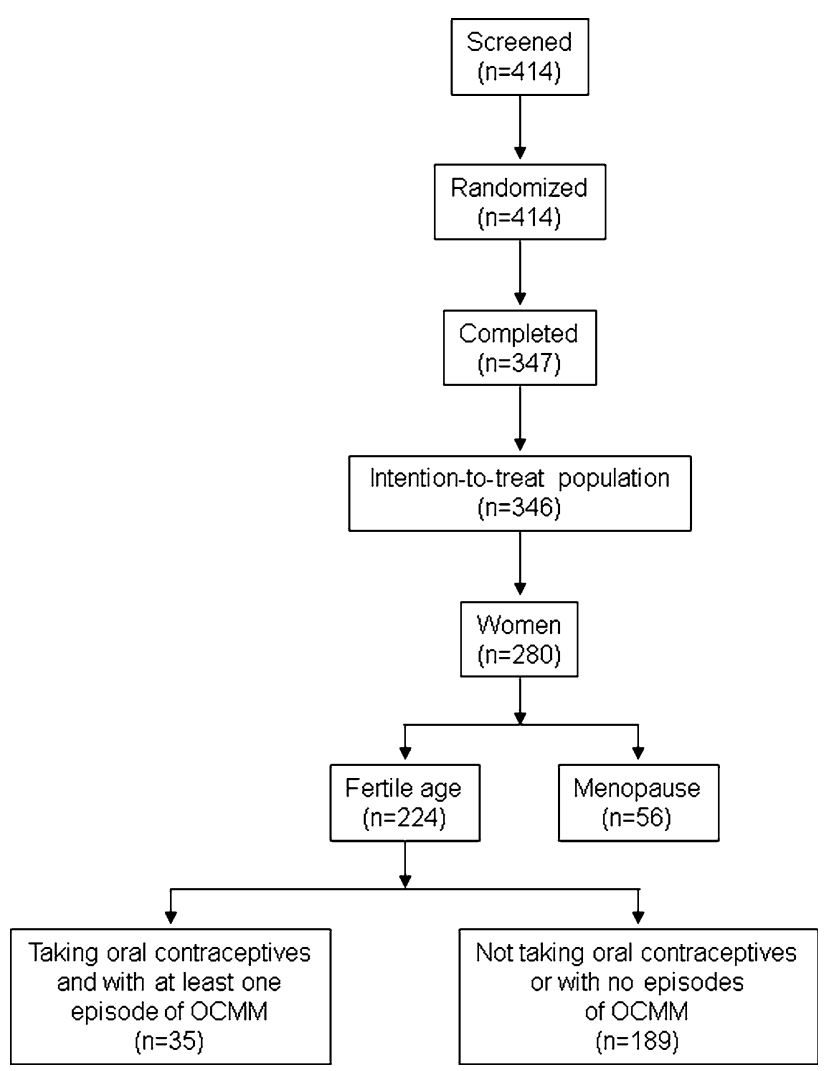

Fig. 1 Flow diagram of the patients throughout the study 
Table 1 Baseline demographic and clinical data of the 35 women with oral contraceptive-induced menstrual migraine (OCMM) and of the 189 women with non-OCMM of the intention-to-treat population

\begin{tabular}{llll}
\hline & $\begin{array}{l}\text { Women with OCMM } \\
(n=35)\end{array}$ & $\begin{array}{l}\text { Women with non-OCMM } \\
(n=189)\end{array}$ \\
\hline Age (years, mean $\pm \mathrm{SD})$ & $35 \pm 9$ & $34 \pm 7$ & $164 \pm 6$ \\
Height $(\mathrm{cm}$, mean $\pm \mathrm{SD})$ & $163 \pm 5$ & $59 \pm 10$ & $\mathrm{NS}$ \\
Weight $(\mathrm{kg}$, mean $\pm \mathrm{SD})$ & $59 \pm 10$ & $16 \pm 6$ & $\mathrm{NS}$ \\
Age at onset of migraine (years, mean $\pm \mathrm{SD})$ & $18 \pm 7$ & $45(24)$ & $\mathrm{NS}$ \\
Migraine attack duration $>2$ days $(n, \%)$ & $7(20)$ & $79(42)$ & $\mathrm{NS}$ \\
MIDAS score $($ mean $\pm \mathrm{SD})$ & $22 \pm 20$ & $29(10)$ & $\mathrm{NS}$ \\
No use of triptans in the previous 3 months $(n, \%)$ & $16(46)$ & $4(10)$ & $\mathrm{NS}$ \\
Migraine attacks with aura $(n, \%)$ & & $\mathrm{NS}$ \\
\hline
\end{tabular}

Data are shown as mean $( \pm \mathrm{SD})$, or absolute $(n)$ and relative frequency $(\%), p$ value refers to the statistical significance of the between-group difference

age. A total of 35 out of the 224 eligible women (16\%) were taking oral contraceptives, treated at least one episode of OCMM with both medications and were thus included in the present analysis. A flow diagram of participants throughout the study is summarized in Fig. 1.

Demographic and clinical baseline data of the 35 women with OCMM attacks and of the 189 women with nonOCMM attacks are reported in Table 1. No statistically significant differences were observed between the two subgroups of women for any of the explored variables.

A total of 144 out of the overall 1,289 attacks occurring in the 224 women in fertile age were classified as OCMM: 73 of the 144 attacks $(51 \%)$ were treated with frovatriptan and $71(49 \%)$ with comparators (8 women treated with rizatriptan, 12 with zolmitriptan and 15 with almotriptan).

As shown in Fig. 2, the proportion of pain free and painrelief episodes at $2 \mathrm{~h}$ were not significantly ( $p=\mathrm{NS}$ ) different between frovatriptan (25 and $51 \%$ ) and the

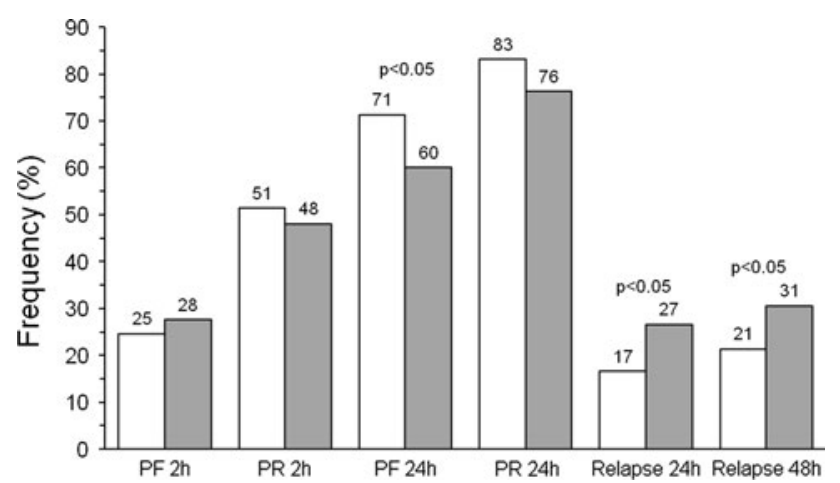

Fig. 2 Main study endpoints in the group of women with oral contraceptive-induced menstrual migraine (OCMM) treated with frovatriptan (open bars) and the comparators (grey bars). Data are reported as relative (\%) frequencies for pain free (PF) at 2 and $24 \mathrm{~h}$, for pain relief (PR) at 2 and $24 \mathrm{~h}$, and for relapses at 24 and $48 \mathrm{~h}$. The $p$ values on top of the bars refer to the level of the statistical significance of the difference between the two study drugs comparators (28 and $48 \%$, respectively). At $24 \mathrm{~h}$, a larger proportion of women treated with frovatriptan were pain free (71 vs. $60 \%$ comparators, $p<0.05$ ) and had pain relief ( 83 vs. $76 \%$ comparators, $p=\mathrm{NS}$ ).

Finally, the rate of relapses at 24 and $48 \mathrm{~h}$ was significantly $(p<0.05)$ lower with frovatriptan $(17$ and $21 \%)$ than with the comparators (27 and $31 \%$ ) (Fig. 2).

\section{Discussion}

As shown in numerous randomized trials, frovatriptan represents a well known and effective option for acute [46 , 11] or prophylactic treatment [15-17] of menstrual migraine. The present study, based on a pooled analysis of three double-blind, randomized, direct comparative, crossover studies [12-14], demonstrates that frovatriptan is clinically effective also for the acute treatment of OCMM, a particular menstrual migraine subtype.

According to our results, the clinical efficacy of frovatriptan at $2 \mathrm{~h}$ was similar to that of the other triptans, with the overall pain-free rates of approximately $25 \%$ and of pain-relief rates of approximately $50 \%$. As expected, such proportions progressively increased during the period of observation, reaching larger values at $24 \mathrm{~h}$ under frovatriptan. In particular, this drug showed a more sustained relieving effect on migraine than the other triptans, with lower headache relapses after $24 \mathrm{~h}$ and even more so after $48 \mathrm{~h}$ and such findings might be explained by differences in the pharmacokinetics of frovatriptan when compared with the other triptans [7, 18].

Very poor evidence is available on the efficacy of triptans in OCMM and no previous direct comparison studies of various triptans have ever been published. In a pilot, open label, uncontrolled study, 20 women treating an OCMM acute attack with frovatriptan $2.5 \mathrm{mg}$ displayed pain-free and pain-relief rates of 10 and $55 \%$ at $2 \mathrm{~h}$, and of 
60 and $75 \%$ at $24 \mathrm{~h}$ [11]. Migraine relapsed within $24 \mathrm{~h}$ in $36 \%$ of patients [11]. In a cross-over, randomized study, $46 \%$ of the women taking $50 \mathrm{mg}$ of oral sumatriptan achieved pain relief at $2 \mathrm{~h}$ and $18 \%$ were pain free, with almost comparable results observed with the suppository formulation of sumatriptan [19].

An additional interesting finding of our retrospective analysis is that immediate and delayed efficacy of frovatriptan in the subgroup of OCMM is superimposable to that previously observed in the whole subgroup of women with menstrual migraine [6].

Despite the interesting results, we must recognize the limitation of the post hoc nature of our analysis. However, to our knowledge, no comparative prospective studies of triptans in OCMM are yet available or have been planned. Our results might be helpful to stimulate the design and implementation of larger direct comparative randomized clinical trials evaluating triptan efficacy in such a specific subtype of menstrual migraine.

In conclusion, our analysis of individual data of doubleblind, randomized, cross-over trials, suggests that frovatriptan and other widely employed triptans share a similar efficacy in the immediate treatment of acute attack of OCMM. However, frovatriptan due to its sustained antimigraine effect, may be more suitable for the management of OCMM than other triptans.

Acknowledgments The present study was supported by Istituto Lusofarmaco d'Italia S.p.A.

Conflict of interest All authors have occasionally served as scientific consultants for manufacturers of frovatriptan, rizatriptan, zolmitriptan or almotriptan. Deborha Pezzola and Dario Zava are employees of Istituto Lusofarmaco d'Italia S.p.A.

Open Access This article is distributed under the terms of the Creative Commons Attribution License which permits any use, distribution, and reproduction in any medium, provided the original author(s) and the source are credited.

\section{References}

1. Lay CL, Broner SW (2009) Migraine in women. Neurol Clin 27:503-511

2. Headache Classification Subcommittee of the International Headache Society (2004) The international classification of headache disorders: 2nd edn. Cephalalgia 24(Suppl 1):9-160

3. Allais G, Gabellari IC, Airola G, Borgogno P, Schiapparelli P, Benedetto $C$ (2009) Headache induced by the use of combined oral contraceptives. Neurol Sci 30(Suppl 1):S15-S17

4. MacGregor EA (2010) Prevention and treatment of menstrual migraine. Drugs 70:1799-1818

5. Balbisi EA (2006) Frovatriptan: a review of pharmacology, pharmacokinetics and clinical potential in the treatment of menstrual migraine. Ther Clin Risk Manag 2:303-308
6. Allais G, Tullo V, Omboni S, Benedetto C, Sances G, Zava D, Ferrari MD, Bussone G (2012) Efficacy of frovatriptan versus other triptans in the acute treatment of menstrual migraine: pooled analysis of three double-blind, randomized, crossover, multicenter studies. Neurol Sci 33(Suppl 1):S65-S69

7. Sanford M (2012) Frovatriptan: a review of its use in the acute treatment of migraine. CNS Drugs 26:791-811

8. Silberstein SD, Holland S, Freitag F, Dodick DW, Argoff C, Ashman E, Quality Standards Subcommittee of the American Academy of Neurology and the American Headache Society (2012) Evidence-based guideline update: pharmacologic treatment for episodic migraine prevention in adults: report of the quality standards subcommittee of the American academy of neurology and the American headache society. Neurology 78:1337-1345

9. Sarchielli P, Granella F, Prudenzano MP, Pini LA, Guidetti V, Bono G, Pinessi L, Alessandri M, Antonaci F, Fanciullacci M, Ferrari A, Guazzelli M, Nappi G, Sances G, Sandrini G, Savi L, Tassorelli C, Zanchin G (2012) Italian guidelines for primary headaches: 2012 revised version. J Headache Pain 13(Suppl 2):S31-S70

10. Loder E, Burch R, Rizzoli P (2012) The 2012 AHS/AAN guidelines for prevention of episodic migraine: a summary and comparison with other recent clinical practice guidelines. Headache 52:930-945

11. Allais G, Bussone G, Airola G, Borgogno P, Gabellari IC, De Lorenzo C, Pavia E, Benedetto C (2008) Oral contraceptiveinduced menstrual migraine. Clinical aspects and response to frovatriptan. Neurol Sci 29(Suppl 1):S186-S190

12. Savi L, Omboni S, Lisotto C, Zanchin G, Ferrari MD, Zava D, Pinessi L (2011) A double-blind, randomized, multicenter, Italian study of frovatriptan versus rizatriptan for the acute treatment of migraine. J Headache Pain 12:219-226

13. Bartolini M, Giamberardino MA, Lisotto C, Martelletti $P$, Moscato D, Panascia B, Savi L, Pini LA, Sances G, Santoro P, Zanchin G, Omboni S, Ferrari MD, Brighina F, Fierro B (2011) A double-blind, randomized, multicenter, Italian study of frovatriptan versus almotriptan for the acute treatment of migraine. J Headache Pain 12:361-368

14. Tullo V, Allais G, Ferrari MD, Curone M, Mea E, Omboni S, Benedetto C, Zava D, Bussone G (2010) Frovatriptan versus zolmitriptan for the acute treatment of migraine: a double-blind, randomized, multicenter, Italian study. Neurol Sci 31(Suppl 1):S51-S54

15. Silberstein SD, Elkind AH, Schreiber C, Keywood C (2004) A randomized trial of frovatriptan for the intermittent prevention of menstrual migraine. Neurology 63:261-269

16. Guidotti M, Mauri M, Barrilà C, Guidotti F, Belloni C (2007) Frovatriptan vs. transdermal oestrogens or naproxen sodium for the prophylaxis of mestrual migraine. J Headache Pain 8:283-288

17. MacGregor EA, Brandes JL, Silberstein S, Jeka S, Czapinski P, Shaw B, Pawsey S (2009) Safety and tolerability of short-term preventive frovatriptan: a combined analysis. Headache 49:12981314

18. Loder E (2010) Triptan therapy in migraine. N Engl J Med 363:63-70

19. Facchinetti F, Allais G, Nappi RE, Gabellari IC, Di Renzo GC, Genazzani AR, Bellafronte M, Roncolato M, Benedetto C (2010) Sumatriptan (50 mg tablets vs. $25 \mathrm{mg}$ suppositories) in the acute treatment of menstrually related migraine and oral contraceptiveinduced menstrual migraine: a pilot study. Gynecol Endocrinol 26:773-779 